\title{
Racism's Back Door: A Mixed-Methods Content Analysis of Transformative Sketch Comedy in the US from 1960-2000
}

\author{
Jennifer $\mathrm{Kim}^{1}$ \\ Independent Scholar, USA
}

\begin{abstract}
Comedy that challenges race ideology is transformative, widely available, and has the potential to affect processes of identity formation and weaken hegemonic continuity and dominance. Outside of the rules and constraints of serious discourse and cultural production, these comedic corrections thrive on discursive and semiotic ambiguity and temporality. Comedic corrections offer alternate interpretations overlooked or silenced by hegemonic structures and operating modes of cultural common sense. The view that their effects are ephemeral and insignificant is an incomplete and misguided evaluation. Since this paper adopts Hegel's understanding of comedy as the spirit (Geist) made material, its very constitution, and thus its power, resides in exposing the internal thought processes often left unexamined, bringing them into the foreground, dissecting them, and exposing them for ridicule and transformation. In essence, the work of comedy is to consider all points of human processing and related structuration as fair game. The phenomenological nature of comedy calls for a micro-level examination. Select examples from The Smothers Brothers Comedy Hour (1968), The Richard Pryor Show (1977), Saturday Night Live (1990), and Chappelle's Show (2003) will demonstrate representative ways that comedy attacks and transforms racial hegemony. Keywords: comedy, cultural sociology, popular culture, race and racism, resistance.
\end{abstract}

During periods of social unrest, what micro-level actions are available to the public? Or, how does a particular society respond to inequities that are widely shared and agreed upon as intolerable aspects of a society? One popular method to challenge a hegemonic structure, and to survive it, is comedy. Quite possibly the most insignificant cultural product that exists to effect serious, lasting change. Richard Pryor's riffs on race in the U.S. are not as socially revered as the voices of his contemporaries like Malcolm X and Dr. Martin Luther King, Jr. But, this outsider status of comedy is its source of strength and reliability. Comedy does not adhere to the usual rules of discourse, or social etiquette. Its aim, in fact, is to target prevailing social norms, beliefs, and in some cases, to give voice to the disenfranchised by re-making race ideologies for the purposes of critique.

While comedy is routinely used for other purposes involving the maintenance of hierarchical systems, psychological tension relief, or as an accessible vehicle to ease social tensions, this potential of comedy to serve as a societal corrective is considered through an analysis of popular American sketch comedy shows, sampled from the 1960s to the 2000s. This paper relies

\footnotetext{
${ }^{1}$ Corresponding author e-mail: jk.sarang@gmail.com.
} 
heavily on theoretical discussions on the general merits and precedence for the use of comedy as a method of popular resistance that is available to the general public, performative (shared), and outside of the realm of typical counter-hegemonic social activity. Empirical evidence from a content analysis of popular sketch comedy shows in the U.S. from the 1960 s to the $2000 \mathrm{~s}(\mathrm{~N}=1,120$ sketches) is also considered, as a form of contextualizing and exploring the theoretical contours of how comedy, in its peculiarities, achieves successful counter-hegemonic gestures, in both discourse and representation. To provide further context, a brief overview of general results from the content analysis will also be described, mainly from the statistical findings to show larger trends, across time.

To evaluate and observe comedy that challenges oppressive racial ideology, an understanding of the particulars of comedy seemed necessary. Comedy presents a topsy-turvy world, but there is technique and skill, and order to the disorder. Some theoretical tools proved useful in constructing a basic understanding of the discursive techniques of comedy. Similarly, the attention to theoretical discussions on discourse complements this paper's focus on the narratives of comedic corrections with specific interests in race and racism. Comedic corrections examined over five decades showed trends in plot, themes, and discursive techniques. From a societal perspective, these examples can often easily become, or did become, points of controversy that are widely circulated and discussed. In other words, comedy that enacts the social critic function of humor to make challenges, criticisms, or to deride oppressive social structures is far more than telling jokes. Their authors and performers work to keep the public appraised of social inequalities certain privileges shield them from having firsthand experience with or knowledge of. In this last regard, comedy offers a current phenomenological portrayal that is widely available, meant to be shared and enjoyed. For these reasons, the next two sections will include a discussion of Bakhtin's literary concepts heteroglossia and double-voiced discourse, and an exploration into a theoretical understanding of comedy. Discussions on identity formation, previous sociological scholarship on comedy, and the relationship between comedy and race in the U.S. appear next, followed by a section on methodology. An exegesis of select examples of comedic corrections to race ideology in the U.S., from The Richard Pryor Show (1977), Chappelle's Show (2003), Saturday Night Live (1990), and The Smothers Brothers Comedy Hour (1968) appear next, ending with a discussion on the consequences of laughter and the ambivalence in interpretation endemic to comedy.

\section{Social Significance of Comedy}

Part of the reason why comedy and humor can wield such a far-reaching presence in countless social contexts and functions is due to its discursive singularity to produce multiple meanings and multiple interpretations. Its strength is in its ambiguity. While most discursive acts aim to achieve clarity and persuasion, discursive techniques in comedic styles purposefully exaggerate and exploit the tension of competing interpretations, meanings, and perspectives. Bakhtin and Holquist (1975/1981) referred to this tension as "heteroglossia", and that present in most literary texts is the conflict and, at times, resistance of various voices - such as author, narrator, and subject. A single novel represents the positioning of many voices, often dialectically, which also initiates the potential for the emergence of previously silenced narratives (Kataria, 2020). Because any narrative expression exists within a hegemonic culture that privileges a dominant interpretation, intent and meaning often become confused. The contention between meaning and interpretation when another person's words enter our own discourse produces doublevoiced discourse, because it produces a fusion of original intentions and transformed conclusions once new material enters the field of play. In parody, the magnitude, depth, and clarity of the other's 
voice is unassailable, while the author's motives must be more individualized and of precise content. The situation is similar in ironic discourse and other double-voiced discourses in which another person's words are used for purposes hostile to a singular interpretation.

Consequently, Bakhtin's examination of parody and its timely companion, laughter, is particularly useful in identifying the emergence of subaltern voices and potential sites of resistance. Parody has the potential to function as the "corrective of reality"; the author purposefully distances themselves from a traditionally authoritative style in the hope of generating new, otherwise silenced, and often subversive versions of reality (Harrison, 2017). The author (or performer, in this case) assumes the voice of an outsider and employs a different language wherein laughter is strategically powerful.

\section{The Materialism of the Spirit}

Comedy is often theorized as containing the remaining aspects of the human realm of representation. For representation, or a "presentation of self" to be successful, the actor must subsume as much of their actual self to the proposed character or projected self, leaving representations that the projected self can never fully incorporate or suppress. This "other side" of representation is made physical in comedy and stands as a type of "objection of conscience" typical of its genre (Zupancic, 2008, p. 26). Contrary to this understanding, Hegel regarded comedy as the physical manifestation of the universal, or essence, thus exposing these universals ${ }^{2}$ to plebian scrutiny, mockery, and laughter. As a mode of a human response to restructure, and in most cases destroy, structural and hegemonic forces, comedy assumes a stand-in role of the universal, and in its "work of the negative", comedy achieves a gravitas and an indispensable importance due to its efficacy to render any universal as "something that is, in the end, utterly empty and contingent" (p. 27). In Hegel's and Zupancic's understanding though, comedy is not the sabotage of the universal, but the material work of the universal. In the action of exposing a universal as subjective and limited, comedy wields the negative power to make these "gods" vanish by extracting it from the reduction of the universal. The pleasure of comedy is watching and participating in this process of making operating social truths and norms vulnerable and declaring their power inert. Comedy is the material expression of the Hegelian spirit (Geist), perfectly liminal, open, and subjective, and superior to its more ponderous counterpart, tragedy, which maintains the fundamental relationship between the subject and the representation of the subject (the character). Zupancic quoted Hegel regarding what comes with the comic consciousness: "all divine being returns, or it is the complete alienation of substance" (p. 28). Rather than alienation of substance from the self or the subject, the substance is alienated from itself. Now, the substance is subject, and through its alienation the promise of consciousness can be realized. The temporal contributions of this move ensure a concrete realization of the spirit: "The universal that does not go through this process is not a true universal, but a mere general abstraction from the concrete. It is only with the concrete that we come to the real spirit of the universal, and we could say that the materialism of comedy is precisely the materialism of the spirit" (p. 38).

This function of comedy to dissect a universal and declare it fair game also occurs at the level of self, thereby affecting the processes of identity formation. Specifically, identity formations grounded in the use of ironic tropes rely on a dialectical relationship between one voice, one position, or personality with others in the service of contrast and displacement to challenge, criticize, and subvert (Perinbanayagam, 2000). Burke's (1969) likening of irony to dialectic echoed

${ }^{2}$ Zupancic lists gods, morals, state institutions, and universal ideas. 
Kim, J.

Bakhtin's treatment of the parodic and ironic forms of discourse as double-voiced, in conflict and contention, and defiant against any single interpretation. The ironic identity then, argued Perinbanayagam, forms a self that is defined by the dialectical relationship of one position and one voice that confronts and contends with other voices and positionalities. The product of this process is an identity that exists as a displacement of other identities, questions them, and ultimately achieves substantive clarity and relevance through opposition and elimination. While the construction of ironic identities occurs constantly, three areas - the carnival, the circus, and the medieval court - provide familiar examples of the fool, the clown, and the jester (Perinbanayam, 2000). Each then also fulfill particular roles within the social world: 1) Fools instigate disorder, parody, and misrule by bucking social conventions through reversals and irreverence, characteristic of the carnivalesque; 2) Clowns employ the grotesque in their disheveled appearance and clumsy demeanor, but through the contrast to the order of tight-rope walkers, a systematic definition and certainty of order is achieved; and 3) Jesters, who also rely on visual effects of their brightly colored and ostentatious costuming, serve a primarily discursive mandate to mock. The importance of ironic identities due to their role of advancing and sustaining subversive positions secures their pertinence when comparing them to other more "serious" identities.

\section{Race Ideology, Representation, and Identity Formation}

While the liberatory potential of comic forms has been demonstrated by Bakhtinian concepts of heteroglossia and carnivalesque for subordinated groups, the particular consideration of race ideology and the technological advances of the mass dissemination of visual images and discourses remains unexplored. The visual aspect of racialization - images of the colonized, the enslaved, the other - long outlived the institutional dismantling of racial apartheid. In Black Looks, hooks (1992) underscored and demonstrated her central premise that there is a "direct and abiding connection between the maintenance of white supremacist patriarchy in this society and the institutionalization via mass media of specific images, representations of race, of blackness that support and maintain the oppression, exploitation and overall domination of all black people" (p. 2 ). These representations are limited, repetitive, and consistently negative. Binary systems of domination subsist on the propagation of these oppressive images, leaving little reason for a reduction or challenge to them (Collins, 2000). While the existence and influence of these negative images are unquestioned, the logic and predominance of a hegemonic racial order based solely on binary oppositions is shifting (Weaver, 2011).

Visual mass media formats like television occupy a particularly vulnerable space of identification, specifically for identities and representations subject to marginalization. Considering cultural identity formation and its relationship to Afro-Caribbean cinema, Hall (1989) established the role of representation in identity formation as active, partial, and ongoing. Identity is not an "already accomplished historical fact, which the new cinematic discourses then represent, we should think, instead, of identity as a 'production,' which is never complete, always in process, and always constituted within, not outside representation" (p. 68). Hall acknowledged the power of representation, not only as a static tool of domination but as a dynamic and, at times, dangerous plane of identification. Positioning vis-à-vis visual representations and discourses of race necessitates a momentary concretization of identity in which meaning is established. Identity is the structuring element of an otherwise malleable, situational self, which arises out of and through dialogic acts (Perinbanayagam, 2000). The anchoring linguistic traits of identity bring a level of constancy to a contingent self and provide continuity among people and situations, differ in their range and depth, and function as methods of categorical differentiation (Smith, 2020; Wildes, 
2020). This view of language and meaning as both momentary and endless derive from Derrida's understanding of language as a boundless field of signification; the continuous deferral of meaning (Davis, 2020). Derrida's departure from understanding language and meaning as fixed and stable, in Hall's application, gain theoretical force through the application of identity formation. An identification, this act of establishing meaning, requires a break in the chain of supplemental interpretations, a "contingent and arbitrary stop" that is strategic, conscious, and relevant.

Diawara's (1988) article "Black Spectatorship: Problems of Identification and Resistance" contended that black male viewers experience psychological "resistance" to the racist portrayals of black male characters in movies such as The Birth of a Nation (1915), Rocky II (1979), 48 Hrs. (1982), A Soldier's Story (1984), and The Color Purple (1985). He described the position of the spectator in response to the cinematic apparatus as "a recourse to the psychoanalytic account of the mirror phase, suggesting that the metapsychology of identification (with the camera or point of enunciation) entails a narcissistic form of regression which leads to a state similar to the infant's illusion of a unified ego" (p. 66). hooks (1992) examined the particular location of black female spectators as potential sites of a particular type of resistance, what she called the "oppositional gaze". Black female spectators are in the unique position, when viewing films, to resist identification with both the characterization of victim and perpetrator, since construction of desire (often synonymous with passivity, or the victim) strictly revolved around a glorification of white femininity, illustrating Hall's conceptualization of identity construction as within representation and not outside of it. Thus, making the visual more than a mirror reflecting who we are, but rather an opportunity to re-construct ourselves, and an important site of identity construction and agency. Race is anything but static or predetermined, but rather an unstable, shifting, and adaptable construct, becoming defined through the existence of various racial projects, which formulate how race is understood, represented and applied, affecting both micro and macro levels of social life (Omi \& Winant, 2015). The cultural format of comedy, as conceptualized by Hegel and Zupancic, is theoretically primed to exploit this connection between representation and identity, as its very constitution means the retreat of the substance, where the self is liberated from construction by the substance. Through comedy, the self-witnesses the mockery and examination of the progenitors and products of representation - the dominant attitudes and the relevant cultural meanings, or the "gods", - and participates in a temporary state of freedom from their power.

\section{Comedy and Race}

Sociological analyses of humor address a multi-faceted array of the relationship between various forms of humor and comedy, such as jokes and stand-up, by demonstrating the serious effects of comical forms on social identities and identity formation, and the maintenance of hegemonic structures of inequality. Akin to other cultural formats, such as music and film, preferences for types of comedy demonstrate processes of boundary construction, as they function similarly, as reliable ledgers of prevailing processes related to social identities, like class and race (Bryson, 1996; Friedman \& Kuipers, 2013; Goldberg et al., 2016). While cultural consumption choices do not necessarily indicate cultural capital a la Bourdieu, an examination of tastes within popular cultural formats (music, comedy, and film and restaurants, respectively) reveals the constructions of symbolic boundaries that work to define cultural superiority and inferiority, both along predominately class lines. Stand-up comedy, interpreted within the context of Durkheim's "cult of the individual", serves to demonstrate the predominance and tension between intrarelational identity formation processes and the influences and needs of the collective (Smith, 2019). Despite the perception of comical forms as ephemeral and insignificant, racist jokes possess 
Kim, J.

rhetorical legitimacy, with interpretative strategies similar to rhetorical mechanisms like metaphor and metonym, that occupy a significant space in maintaining and justifying racist logic (Weaver, 2010). The discursive malleability of comedy advances the Bakhtinian subaltern perspectives in American black satire, giving voice, humanity, and visibility to the traumatic effects of racism on mental health (Guerrero, 2020). Contemporary joking culture is also a malleable social space in which the permission to participate in racist joking is allowed and encouraged, bolstered by the myth of a post-racial society (Perez, 2013).

While Weaver (2011) convincingly demonstrated the rhetorical power of racist jokes, he also included a preliminary examination of "reverse discourse" strategies of black and Asian comics in the U.K. and the U.S. Noting the popularity of examining the potential of humor as a form of resistance, the conceptualization of resistance humor as a vehicle for the resolution of ambivalence receives special attention via the work of Bryant (2006) who discussed the use of humor as resistance by Czech nationals under Nazi occupation (Weaver, 2011). The most successful contemporary examples of race-based resistance comedy ensure a similar form of the resolution of ambiguity in interpretation. Welcome (2010) conveyed the strategic ways black female comedian Moms Mabley (also discussed herein) capitalized on the temporality of the comic context to resist and redefine representations at the intersections of racism and sexism. Covering a wide range of national, historical, and political contexts, the effectiveness of humor in solidifying collective identities in social movements and social agitation conveys the overarching significance of humor in social processes (Rehak \& Trnka, 2019).

The resolution of the debate over the fully dominating or liberatory aspects of humor is less the focus of the following analysis and discussion, since as is the case with most cultural objects and meanings, the answer is humor most likely does both. The social significance of humor is clearly demonstrated by the wide range of the ways in which it functions to both digest and interpret other social structures, like class and race. And while Weaver's (2011) rhetorical analysis of racist jokes proffered a convincing case for the function of comedy in maintaining and continuing racial supremacy, an analysis of the cultural meanings of comedy over time, with an empirical focus on the transformative potential of comedy in race ideology, remains relatively unexplored. Davis (1993), Krefting (2014), Quirk (2015), and Smith (2018) have contributed profound findings in this vein, manifesting the ways in which jokes and comedy culture both challenge, reflect, and interact with operating social structures. Comedy is a "social fact" that possesses "concrete autonomy" that views culture as a "structural factor that must be accounted for in historical explanation" (Kane, 1991, p. 55). While the functions of humor are manifold, the significance of humor to structural processes (boundary making, identity formation, and structures of inequality) has been adequately evidenced. My study continues this view of comedy as an important characteristic of cultural processes that, as noted by Kane, are not epiphenomenal, but possess both analytic (an independent structure of culture) and concrete (historical specificity) autonomy.

\section{Methodology}

The qualitative examples below are culled from a larger data set that included a statistical analysis (crosstabulation) of 25 variables and narrative/discourse analysis of 1,120 sketches. As the primary level of comparison, sketch comedy shows consistently linked to controversy or labeled as "controversial" by news and popular media sources were selected due to their notoriety and subsequent exposure and familiarity in wider societal and cultural consciousness. Using controversy as a proxy for indication of social agitation or disruption (transgression), the most 
controversial shows in each decade ${ }^{3}$ were selected: The Smothers Brothers Comedy Hour (1960s), The Richard Pryor Show (1970s), In Living Color (1990s), and Chappelle's Show and Da Ali G Show in the 2000s. The first year of syndication for each show was analyzed in addition to all other sketch comedy shows $(\mathrm{n}=15 \text { shows })^{4}$ that aired contemporaneously, for context and comparison. ${ }^{5}$

Quantitative variables included: aspects of programming (e.g., broadcast night and TV channel); racial and gender proportions of characters; race and gender of writers, producers, and directors; racial discourse, including implicit racial discourse; use of racial and homophobic slurs; racial and sexuality performance and drag; type of humor (e.g., parody, surreal, or physical); and humor techniques ${ }^{6}$ (e.g., logic, such as reversal and ridicule, language, such as irony and repartee, and identity, such as mimicry). Within a particular season and an episode, a comedic segment (e.g., sketch or stand-up) was counted as a discrete unit of analysis. The qualitative analysis addressed techniques of narrative (characterization and plot), discourse (characteristics of language and connections to plot), the semiotic (deep structures, latent meanings, and signifying processes), interpretive analysis, and representational elements, such as costuming, camera perspective, and character performance. After sorting sketches that contained racial discourse, I followed Weaver's (2011) metric of resolution of ambiguity in interpretation to further sort sketches into three categories - ambivalent, transgressive, and hegemonic. To account for some of the subjectivity in interpretation inherent in qualitative, textual analysis, the bar was set quite high for sketches that contained transgressive messages regarding race ideology, amounting to only $4.5 \%(n=50)$ of the sample. Thus, the counter-hegemonic examples demonstrated strong instances of the resolution of ambiguity in meaning. For example, basketball superstar Bill Russell and Flip Wilson, in a sketch on The Flip Wilson Show (1972), sit down to a game of chess and the following conversation ensues:

Wilson: [Reading from a rule book] In the game of chess, there are always two sides, black and white.

Russell: [Laughing] That means we can't play.

Wilson: They're talking about the pieces. Now, do you want white or black?

Russell: Which is better?

Wilson: Neither one is better. No advantage either way.

Russell: Oh okay, then I'll be black. Because black is beautiful.

Wilson: That sounds so nice. Okay. I'll be white. Uh...white moves first.

Russell: Wait a minute. I thought you said there's no advantage.

Wilson: Well, uh, moving first is not a particular advantage, suppose we went to a mine field.

Russell: Oh okay, go ahead, move. (Kay, 1970-1974)

\footnotetext{
${ }^{3}$ There was a relative lack of reporting on, or identification of, controversial sketch comedy shows in the 1980s by news and popular media sources.

${ }^{4}$ Both The Carol Burnett Show and Saturday Night Live spanned multiple decades, the 1960s and 1970s for The Carol Burnett Show and the 1970s, 1990s, and 2000s for Saturday Night Live, but were each only counted once.

${ }^{5}$ Comparison shows are: in the 1960s, The Carol Burnett Show; in the 1970s, The Carol Burnett Show, The Flip Wilson Show, and Saturday Night Live; in the 1990s, The Kids in the Hall, The Ben Stiller Show, Idiot Box, and Saturday Night Live; and in the 2000s, Mind of Mencia, Blue Collar TV, Cedric the Entertainer Presents, Mad TV, and Saturday Night Live.

${ }^{6}$ Adopted from Berger's (1995) categorization of comical rhetorical techniques.
} 
Kim, J.

In this example, it is because of the statement "Because black is beautiful" that the sketch was coded "transgressive", and while a reading of the statement as only referring to the color black and not black people is possible, the clarity and intent of the statement is undeniable. Furthermore, a statement that does privilege black over white within a white supremacist cultural context is transgressive, in its own right, regardless of context or interpretation.

While a deeper exploration of the quantitative analysis is not possible, some observations are helpful for adding breadth to the qualitative examples discussed below. In general, sketch comedy in the U.S. from 1960-2000 is predominately male (appearing in sketches $66.2 \%$ of the time) and white $(66.6 \%)$. Sketches that contain racial discourse occur $24.3 \%$ of the time and most sketch comedy does not contain racial performance $(6.6 \%)$ or use racial slurs $(5.8 \%)$. The frequency of racial discourse in sketch comedy is related to time, showing a steady increase in the appearance of racial discourse.

Table 1

Racial Discourse by Year (\%)

\begin{tabular}{lllll}
\hline Racial Discourse & 1960 & 1970 & 1990 & 2000 \\
\hline Yes & 17.5 & 24.2 & 15 & 41.9 \\
No & 82.5 & 75.8 & 85 & 58.1 \\
Totals & 100 & 100 & 100 & 100 \\
$(N)$ & $(120)$ & $(360)$ & $(387)$ & $(253)$ \\
\hline
\end{tabular}

Note. $N=1,120$. Goodman and Kruskal tau $=0.15$.

$\mathrm{P}<0.001$.

It is of note that the production of racial discourses in the 1960s and the 1990s are so similar. Previous research has confirmed the relationship of racial visibility in narrative and representation to wider societal racial climates, with less visibility of non-white characterizations during racially tense times, and confirms the relatively low rates of racial discourses in sketch comedy during the 1960s and the 1990s. Pescosolido et al. (1997) demonstrated the relationship between racial protest, or attempts to reconfigure racial hierarchy, and a virtual absence of black characters in children's books, from 1958-1964, with a spike of representation in the early 1970s, and a stabilization of representation from 1975-1993, at 20-30\% of the time. Linking the influence of societal racial climates to the roles of cultural gatekeepers and the frequency and manner of black representation in these books is echoed in comedic productions, with some divergences. If sketch comedy followed a similar pattern over time, the production of racial discourses should have maintained a stabilization of the presence of racial discourses from the 1970s to the 1990s. Lower levels of racial discourse are expected in the 1990s, a virtual volcano of racial examination and brutality. ${ }^{7}$ Instead, sketch comedy shows, sampled around the most controversial shows in each decade, seem to have the ability to maintain, comparatively, a steady presence from the 1960s to the 2000s and to double by the 2000s. This ability to have some independence from the wider societal context is unique to comedy when considering the relationship between racial protest and current cultural productions.

Through the qualitative analysis of more than 1,000 sketches, the following sketches are representative of characteristics of counter-hegemonic comedy. In order of appearance, these sketches take command of the comedic context to reshape the semiotic, to enact heteroglossia as an empowering method to embolden the voice of the disenfranchised, to serve as a reminder of the

\footnotetext{
${ }^{7}$ e.g., The OJ Simpson trial, Anita Hill and Clarence Thomas, and the vicious beating of Rodney King and the ensuing LA Uprising/Sa-I-Gu (see Yi \& Hoston, 2020 for an explanation of this alternate use of "LA Riots").
} 
full spectrum of race ideology by including perspectives that fall outside of the black-white binary, and to further expose how deeply racism permeates an existence, only to simultaneously find levity in it.

\section{Claiming Representation}

In a series of sketches that span several episodes, Richard Pryor plays a gunslinger cowboy in a setting evocative of the "Wild West" portrayed in so many beloved Westerns. In these sketches, Pryor's cowboy is not limited to the role of the black cowboy, although his difference is still noted with an outsider status. Furthermore, these sketches contain no racial discourse, (47.5\% of sketches contained racial discourse in The Richard Pryor Show (1977) sample) but make important contributions to reinterpreting the boundaries regarding how classic American, so important they are revered, images and symbols are raced. The cowboy, a symbol of strength, resilience, hard work, and fearlessness, is the epitome of masculinity in American society. The cowboy does not complain, does not look for handouts, and is the master of his own future. Coupled with these virtuous qualities is the sort of noble violence that is also integral to the cowboy symbol through the defense of their honor, sometimes at the slightest of offenses, through gunfights. A continuation of the tradition of dueling as a means to solve conflicts and to affirm masculinity, the Western gunfight served to maintain systems of power and order in still developing frontier towns and to establish the terms of defining masculinity in a developing nation. For a national symbol though, the cowboy is constructed in clearly specific gender lines, in addition to sexuality and racial demarcations. The cowboy is not only hyper-masculine, but hyper-heterosexual and white.

In Pryor's reinterpretation of the cowboy, even in the absence of discursive characteristics, he succeeds by representing a black male as a cowboy, not a cowboy who happens to be black. In two separate sketches, Pryor reinterprets and therefore challenges the strict racial boundaries that surround the cowboy symbol, without the use of discursive techniques. In fact, in the first example, Pryor's character is defeated by three white cowboys in an altercation that leads to his death. In the sketch, a lone gunslinger (Pryor) approaches town as three white cowboys/gunslingers heckle him from a porch, calling him "gringo" and asking him how his "ass" is. Pryor asks angrily whether they mean his donkey. The three white gunslingers answer the black gunslinger's insolence with heavy pistol fire while the lone gunslinger struggles to remove his pistol, seeming to be glued to his holster. The three white gunslingers jeer:

White gunslingers: Hey gringo, how's your ass?

Lone gunslinger (Pryor): You mean my donkey? It wasn't nice to kill my donkey. (Urbisci, 1977)

Receiving gunfire enough to kill a single man many times over, the black gunslinger falls to the ground impossibly slowly, until eventually falling dead. In the second gunslinger sketch, three gunslingers (Pryor and two white males), also on a porch, compete with one another over superiority of skills with their pistols. Pryor's black gunslinger challenges a fellow white gunslinger to "prove it". The white gunslinger answers his challenge by expertly shooting two glass bottles on the ledge of the porch. He turns to Pryor's character with a proud smile to which Pryor's character motions "so-so" with his hand. The remaining gunslinger needing to "prove it" walks in front of the two gunslingers, who have already proven themselves, lifts his hat and shoots himself in the stomach. The black and white gunslinger look at each other with expressions of confusion and 
Kim, J.

disbelief and slowly back away still facing the gunslinger dying from a self-inflicted stomach wound.

The significance of both of these sketches is not whether the black gunslinger died or stayed alive, or whether he overcomes insurmountable obstacles due to his marginalization, or even whether he uses yet another space clearly defined in racial terms to critique these limitations. The reinterpretation in these examples is more subtle and quite clever. Clearly, the situations are comedic and Pryor's expressive face and bodily contortions make both sketches incredibly funny, even in the one that he dies. Yet, the overall feel and plot of both of these sketches closely mimicked many scenes from Western movies and other popular memories of the Wild West era and could have easily been dramatic, climactic, and crucial scenes. All of these factors serve to decenter a deeply ingrained, treasured hallmark of American masculinity and whiteness vis-à-vis the cowboy/gunslinger symbol by including in these past narratives and memories an alternate representation of the gunslinger. Neither of these sketches reference the blackness of Pryor's character - in the first sketch, the hecklers invoke "gringo", to mark this stranger gunslinger as an outsider, but not due to his race. In fact, the white gunslingers adopt a term developed by indigenous populations as acts of resistance, making the comic irony and incongruity of the situation that much more layered. Unlike the paragon of family values, principles, and goodness that The Cosby Show projects or the representations of blacks in the 1950s as servants, deadbeats, or criminals, these sketches offer us a third way. ${ }^{8}$ Pryor's black gunslinger is both courageous and flawed, masculine and goofy, and an outsider and an insider. In other words, Pryor's black gunslinger is not immediately raced or made a derivative of "real" white cowboys and gunslingers, his presence, through the re-articulation of representation, creates an alternate understanding of the range of images and identities black males have access to. In this case, there is no discursive mandate for challenging the racial and cultural hegemony of this symbol - through representational and narrative choices, Pryor succeeds in expanding the boundaries of what a cowboy looks and sounds like while simultaneously changing what it means to be a black male. In his Wild West, black males are just as viable as cowboys and gunslingers, just as normal and obvious.

\section{Forcing Heteroglossia}

Dave Chappelle does not make use of a dialogic context by directly entering it, but rather forces heteroglossia by adding to single-voiced discourse retrospectively. During a sketch on Chappelle's Show (season 1, episode 4) he plays clips from his guest appearance on a show titled, "Angry White Men", hosted by Donohue, stopping at various points to say what he was unable and unwilling to say at the time. Initially, he explains, he was extremely interested to engage in dialogue about race in the United States, but that he "gave up" in the middle of the show since it became "the same person saying the same thing over and over again, instead of it being a conversation, which is why I agreed to go on in the first place." Chappelle does not engage with a white male audience member who expresses:

\section{I think one of the underlying issues here is that affirmative action forces somebody-you're forcing people - and anytime you force somebody- I don't know about you gentlemen - but, I don't like to be forced. When I'm pushed, I'm only pushed so far - and then I push back.}

\footnotetext{
${ }^{8}$ See Jhally and Lewis (1992) for a discussion of The Cosby Show and Gray (1995) for images of blackness in the 1950 s.
} 
The clip pauses and Chappelle delivers the response he would have said:

Forced? Oh, you mean like, slavery-forced? Remember that thing when you forced us to work for you, for 100 - what do you think black people were like, "No problem boss, [in a stereotypical, exaggerated black southern accent], I'd love to!" Man, that was infuriating. (Armour et al., 2003-2006)

Chappelle challenges the dominant, white (male), both de jure racist and colorblind racist, perspectives by entering that world, but he leaves that world altered, fragmented, and discontinuous. In a sense, he re-opens the "arbitrary and contingent" moment of identity formation as described by Hall back to the potential for re-articulation through the Derridean deferral of meaning. At least four potential identities exist simultaneously through Chappelle's commentary the Chappelle on the Donohue show who is silent, passive-aggressive, and defeated; the Chappelle who is assertive, ironic, somber, and incredulous; the white male asserting his frustrations with, to him, an anachronistic need for racial equality who feels his white privilege threatened by the "others"; and the white male, who after Chappelle's criticisms, both naively and callously, forgets with convenience the altered meaning of something as seemingly objective as the word "forced". The visual representations in which identities are forming against are doubled, as we receive them simultaneously. The re-examination, and thus contention, with an adamant closure of meaning is temporarily weakened.

Interjecting commentary and adding a missing or subordinated voice is also carried out during Chappelle's expressed anger over the WB network's mascot, a dancing frog with a top hat and cane. Part of another sketch in which he parodies the extreme lengths that reality TV shows go to establish drama, Chappelle is seen dancing, mocking the style the network uses to advertise new shows or to continue interest in current shows in between commercials. After the last installment of the show "Zapped", the WB frog sits on Chappelle's shoulder, drawn to evoke the costuming of minstrels, and sings out "Mammy" in an exaggerated way, while lifting his top hat. After the sketch, Chappelle responds to the audience's reaction of surprise and nervous laughter:

That fucking frog. I hate that frog. What?! I can't make fun of the frog? They don't do that shit on white networks, as soon as a black man, you have dum-dum-dum-dum [singing and taking his cap off] oh, the WB! I like chicken. The most racist shit ever. Welcome back niggers [in a mocking, singing voice] to the WB! (Armour et al., 2003-2006)

While this example is not as lengthy or substantively explored as Chappelle's commentaryafter-the-fact on the Donohue show, this still represents a powerful and effective way of achieving transgression in already written racial discourse, in this case, racist representation and semiology. $\mathrm{He}$ voices a perspective that is utterly unobscured even though the interlude still remained very funny and critiques the way television, even its images and styling, is raced and racist.

\section{Beyond the Black-White Binary}

Chris Rock, a part of the cast of the $16^{\text {th }}$ season of Saturday Night Live (1990), despite limited exposure (Rock appeared in $1.5 \%$ of the total sketches, $n=180$ ), often delivered pithy and biting critiques of race in the media. Rock, as a sports correspondent, struggles with wanting to 
Kim, J.

place a bet on the upcoming Hollyfield and Buster Douglas fight and not understanding why Douglas is not favored more. He continues by saying that white males are not good at boxing, reasoning:

The lower you go on the social ladder, the better you can fight. For every Puerto Rican fighter, there's an American Indian waiting to kick his ass. I feel so sorry for the American Indian, we took, I mean we didn't, you took their land and now they have nothing, everyone exploits the Indians, we got Mazola, Cleveland Indians, the Redskins - the Redskins - that's not nice, that's a racial slur, that's kind of like having the New York Niggers, okay? Remember the commercial the Indian had a tear in his eye because of pollution, he wasn't crying because of pollution, he's crying because you raped his wife, okay? I don't think he was crying because there was a can on the ground, I mean, huh, Dennis [Miller], what was I talking about? (Michaels, 1975-present)

In the above example, Rock, playing a sports correspondent, likens the facility to box to the racial hierarchy in the U.S., provides the most transgressive racial discourse regarding Native Americans out of the entire sample of sketch comedy shows examined herein over five decades. ${ }^{9}$ He demonstrates the nuance of race and racism in the U.S. by demonstrating its effects beyond the black-white binary, a point not frequently accomplished in other forms of transgressive racial discourses and representations. In his analogy, the least (and most privileged) talented at boxing/fighting are whites, while blacks are better, and, "for every Puerto Rican fighter, there's an American Indian waiting to kick his ass."

Given the near dearth of transgressive racial discourses and representations that go beyond the black-white binary, Rock's more visionary critique of race ideology is unique and necessary. He effectively incorporates the appropriation of the noble savage image in terms of the language of a black-white ideological understanding of race when he describes the history of dispossession and the shape of racism toward Native Americans. A form of cross-racial solidarity encouraged by Takaki (2000) is accomplished here as he analogizes racism toward Native Americans by invoking the extremely charged "nigger" to "redskin", in the comedic climactic moment in his short performance. Furthermore, he is clear to establish the boundary between whites and blacks in their historical culpability in the genocide, land dispossession, and the punitive programs of forced cultural assimilation, by moving from "we" (Americans) to "we didn't" (blacks) to "you" (whites). Rock also touches on the inter-connectedness of race, gender, and sexuality, argued by Nagel (2003), through mocking the use of the noble savage image by white-dominated advertising, a point missed in the only other two sketches (on Chappelle's Show and The Richard Pryor Show) with counter-hegemonic material regarding Native Americans in a 50-year period.

\section{Re-articulating the Everyday}

In her second appearance performing stand-up on The Smothers Brothers Comedy Hour (season 2, episode 23), Moms Mabley tells a variety of stories including a dying woman who confesses her infidelity to her husband who already knew so had poisoned her, a classroom where a white teacher asks two white students to spell "cat" and "rat" and a black student

\footnotetext{
${ }^{9}$ The other two examples are stand-up by Charlie Hill on The Richard Pryor Show and a sketch on Chappelle's Show.
} 
"chrysanthemum", a wake (Mabley has a short aside where she says she is ignorant to whether white people have wakes, but that "we do") wherein a grieving widow finds out her husband was unfaithful and so changes the tribute on his casket from "rest in peace" to "rest in peace, until we meet again", and facing death row, a white bank robber confesses to a black bank robber that he is afraid and "can't take it like a man" because he is not "used to it".

Encountering the kind of blatant racism and hostility as told by Mabley in the classroom caused black students in the 70s and 80s to drop out, and those that did manage to gain entry into white colleges and universities often left without a degree (hooks, 2003). A critical race consciousness, largely incompatible with the overt and covert racist climate of educational institutions, created an unbearable environment leading either to assimilation or departure (LaPaglia, 2018). Mabley's characterization of the unequal treatment of white and black students where the main objective is to confirm beliefs regarding black inferiority needs little comic manipulation. Grounded in a situation that all too closely mimics real life in real time directly contributes to its comic tenability and, importantly, does not obscure its transgressive potential. Similar to Chappelle, Mabley counters dominant, single-voiced discourses (black students are inferior) by entering the comic space which tolerates multi-vocality and oppositional perspectives (white teachers are racist; black students are just as capable; or whiteness is a privilege), to challenge and ultimately to re-fashion meaning of the original and hidden dominant discourse.

A racist judicial system is also examined in her stand-up along with an allusion to the linkages between white and black masculinities, which relies on a similar form of black ${ }^{10}$ humor as the chrysanthemum joke, where the source of laughter is how ridiculous it is that the instance in which a black male has an "advantage" over a white male revolves around the reality that dying or the constant threat of bodily harm and violence is a normal and common aspect of the black male experience. It is within this context as well that Mabley's other jokes are interpreted - not as reinforcement of racist logic that the heterosexual love and sexuality of blacks are degenerate, characterized by infidelity, treachery, and ultimately deadly violence - as alternate stances to the same representation. Mabley does not transform or even challenge this stereotypical portrayal of black heterosexual love, but she also does not deride it, since she claims it and laughs alongside it, not at it. The issue at hand is not to determine whether Mabley has internalized this stereotype of racist beliefs, but rather to examine the ways in which she simultaneously acknowledges its presence while changing the typical route of interpretation toward repulsion, to humorous and tragic stories of bickering couples; they acquire the depth and relatability absent from stereotypy used to uphold racism. The subtle move she employs can be likened to the stark differences in interpreting the same actions between men and women due to operating sexist cultural morays. The actions do not change, but our capacities to read them similarly is obscured by the dictates of gender norms and roles. Similarly, Mabley recounts vignettes of love, betrayal, and loss - all too familiar narratives of romantic love in general - and set apart from the obscuring effects of racist ideology, these are not black stories, they are stories told from the perspective of a black female comedian. Just as stories about persons occupying positions of hegemonic privilege ${ }^{11}$ retain their individuality

\footnotetext{
${ }^{10}$ I follow Goldstein's (2003) use of the category "black humor" in her study on women's resistance and popular culture in the favelas, or shantytowns, of Rio de Janeiro, as understood through its usage by Andre Breton in the Surrealist movement as a formidable political weapon.

${ }^{11}$ I refer here to positions of privilege like gender (male), race (white), class (middle and upper classes), and sexuality (heterosexuality). In many cases though, as the pioneers of intersectionality (Collins, Crenshaw, Davis, and hooks) have demonstrated, various points of privilege intersect and manifest depending on the social, cultural, and economic situations, as black males can hold privilege in their gender and white females in their race.
} 
Kim, J.

and do not become overarching truths (stereotypes and controlling images) about others occupying a similar position.

\section{Laughter and Ambivalence}

The resulting ambivalence in interpretation from addressing representational and discursive transformation is most likely attributed to the complications that arise from addressing change on intersecting planes of subordinated social identities. Efforts to reclaim and redefine the contours of meaning also manifest through the proliferation of female presence in hip hop and rap music videos. Hip hop and rap, once a site for repressed creative expression and validation of blackness and at other times bemoaned for its glorification of violence and negative stereotypes of black males and culture, also drew attention and criticism for hypersexualized images of black women and their consistent objectification in lyrics and music videos. By focusing on black female performers, Emerson (2005) examined the ways in which black women used popular culture and found that in some instances, they reproduced gender and racial oppression, while others were more successful at re-definition and opposition, and a number of attempts produced ambivalent results. Her conclusions demonstrated the theoretical commonsense of Kellner (2020) and Mukherjee et al. (2019), that whatever the maneuver of cultural negotiation, they exist within the confines of dominant common sense, whereby some hegemonic reproduction is unavoidable. Therefore when Missy Elliot advances her counter-hegemonic narratives, appearance, and style of a powerful, sexually mature, and confident woman, she does so against the backdrop of a peep show, reinforcing traditional and oppressive styles of heteronormative male sexual dominance and desire. Rather than a clear reproduction of patriarchal values, Emerson contended that in efforts to construct an alternate discourse and representation that did not submerge (or erase) sexuality under gender equality resulted in a seeming contradiction. While not complete, or perfect, examples like Missy Elliot work to challenge and dislodge the stability and power of the Jezebel stereotype and controlling images of black female sexuality as insatiable, uncontrollable, and deviant.

In her widely cited contribution to feminist theory, Gender Trouble, Butler (1990/2008) opined in the chapter "Subversive Bodily Acts", that "[p]arody by itself is not subversive, and there must be a way to understand what makes certain kinds of parodic repetitions effectively disruptive, truly troubling, and which repetitions become domesticated and recirculated as instruments of cultural hegemony" (p. 189). This theoretical investigation is undertaken by Gogan (2009) in the chapter, "Laughing Whiteness: Pixies, Parody, and Perspectives" found in a collection of essays devoted entirely to analyzing contemporary comedian, Dave Chappelle. Gogan tackled the controversial nature of Chappelle's narration of the steps leading to his exit from Chappelle's Show, in particular, Chappelle's recounting of his discomfort with the laughter of a white spectator who "laughed particularly loud and long" (p. 72). This characterization, widely consumed in a 2005 Time magazine article, ultimately raised questions about the culpability of Chappelle in reproducing racial stereotypes and an insidious counter-characterization that served to excuse the many spectators, often white, who almost joyfully participated in these reproductions, reflecting the durability of racial hierarchy. It is within this area that Gogan's analysis was less successful when considering cultural controversies surrounding race and racism. An analysis focusing on the contours of laughter from whites in response to comedy on race and racism is not in question, nor the conceptual application of Butler's challenge to pin down differences between parodic responses to hegemony. Gogan succeeded in making laughing a serious matter and presented an illuminating consideration of laughter as "extra-linguistic" and argued that in "sketches that target race, laughter escapes the confines of language and thereby creates an extra-linguistic space in which individuals 
can confront authority by maneuvering in, around, and/or about racial markings" (p. 85). He made important contributions to legitimating parodic responses to hegemony, continuing Bakhtin's conceptualization of parody as an effective discursive response to dominating authoritative logic and discourses. Yet the assumption that the "extra-linguistic" nature of laughter escapes the trappings of race ideology, whereby treating things as uniform like "language" or "laughter", unduly sidesteps race ideology, even as it discusses race through comedy. In a very real way, the laughter of whites and the laughter of non-whites can never be the same, can never be contemplated without the acknowledgment of positions in the racial hierarchy, and can never be understood with any semblance of post-racialism. Perhaps it is for this reason that Gogan asserted that 'laughter's subversive potential depends neither on context nor reception [and that] language cannot be read or written as parodic, subversive alleged, racist-sounding, too-hard, or anything else for that matter, because laughter does not signify in any shared fashion" (p. 77). The deafening absence of critical race perspectives, such as Stuart Hall and bell hooks, produces an incomplete deliberation of the complicated relationship between contemporary comedy and racial politics.

In The Rhetoric of Racist Humour, Weaver (2011) certified the rhetorical power of racist joking on the internet, but he remained less certain of the rhetorical legitimacy of counterhegemonic comedy that used "reverse strategies" to challenge race ideology. One of the overarching theoretical contributions in his nascent analysis of the two extremes of comedic discourse on race resulted from the discourses that could be found in the middle. These ambivalent discourses of race (Weaver used Da Ali G Show and the Danish Prophet Muhammad cartoons as prime examples) led him to conclude that a general increase in ambivalence, typifying what Bauman considered the "liquid" state of modernity, about race may lead to a new formation of racism, what Weaver called "liquid racism". Bauman regarded the state of modernity as an evergrowing state of the creation of ambivalence, via a semantic need to categorize, ultimately leading to further fragmentation and the creation of a semantic void. Following this and noting the increased amount of semantic slippage inherent in comedy, Weaver defined liquid racism as a novel formation of contemporary racism, distinct from cultural, biological, or even colorblind racism. According to him, it is fluid, difficult to collect or identify because it may escape or dissolve before it can be contained, and is explicitly encouraged or given coverage in mass media forms. Exacerbated by comedy's interpretive ambiguity, Weaver argued that liquid racism in humor "dilutes" any chance for interpretive clarity, putting even more at risk the potential for critique from the reader. In other words, only counter-hegemonic comedic discourses on race and racism with clear interpretive closure have any guarantee of rhetorical legitimacy. But, even Weaver admitted that a racist interpretation of material from Chris Rock, an example of successfully "resolving" ambivalence, is not only possible, but likely if we take the magnitude of the race construct seriously.

Rather than shun ambivalence, or attempt to guarantee interpretation, I propose the fusion of what Gogan termed the "extra-linguistic" nature of laughter and the moves toward a neoclassical social theory, grounded in self-irony, as proposed by Eyal et al. (2003). An ironic, historical approach to social analysis, as long as it is rooted in self-irony, encourages reflexivity and discourages the elevation of any one standpoint or logic. Therefore, the ironic researcher, as a practice, distances themselves from macro and micro level hegemonic meanings and truths and becomes empathetic to the position of the "other". As a result, ironic views and analyses of the social world have a central role to accept all positions and to challenge hegemonic meaning, however they may manifest. To treat a surge in ambivalence, or a surge in the related search for meaning in this theoretical framing is not relativist, or the cynical portrait that Weaver or Bauman predicted. If we look to the social role of the comedian as a site of the production of ambivalence, 
Kim, J.

or taken in another way, the production of alternate positions, then the increase in ambivalence does not necessarily mean a determinate loss of meaning. Rather than holding the ambiguity in comedic forms responsible for commonsense interpretations laced with clear vestiges of de jure, cultural, and colorblind racism, perhaps the location of accountability should rest on those interpretations and how our social formation supports them.

\section{Conclusion}

Exploring the particular cultural meanings of counter-hegemonic sketch comedy reveals the potential of the cultural format to remake complete hegemonic continuity; perhaps for this reason, Hegel considered comedy a crucial manifestation of the processes of human consciousness. Indeed, the sketches discussed above are exactly at the intersection of a critical assessment of race ideology and the development of an alternate interpretation, a transformed representation, of the consciousness that both accepts, challenges, and reinvests cultural meanings with multi-vocality. In these representative comedic examples, the strict trappings of hegemonic cultural production are weakened as are their accompanying cultural symbols and meanings. The others, those sidelined by racial ideology and hierarchy, claim a part in the production of knowledge. The cowboy, an integral symbol to American nationhood, pride, and a foundational element to white hegemonic masculinity; the power of single-voiced discourses that perpetuate racial hierarchy and post-Civil rights era racism; the myopic and alienating trappings of a black-white binary; and the sanctity of racist tropes and representations are all questioned, often revealing their rotting infrastructure of logic, and the production of stories, perspectives, and meanings, previously silenced or subordinated, is possible. When Chappelle "forces heteroglossia" he not only contends with racist discourse, he also creates existential spaces for the release of "inappropriate" emotions like anger and indignation, while also cultivating the expansion of the boundaries of identity formation. Identity formation vis-à-vis popular culture representation often focuses on the serious forms of narrative, like drama, tragedy, and the news. These inquiries and their findings are paramount, convincingly suggesting that even though structure is determining, the process is contingent, it is arbitrary, and it is vulnerable to transformation. For this reason, comedic corrections and interventions via mass media are a crucial point for gaining insight on contemporary issues of race and racism, as well as a site of resistance and change.

Recently, in The Bird Revelation (2017) ${ }^{12}$, Chappelle took a somber moment in between a typically belt-busting delivery, to reflect on societal reactions to his comedy and the societal purpose of his role as a comedian. He noted, "[e]verybody gets mad because I say these jokes, but you gotta understand that this is the best time to say them. More now than ever, and I know there's some comedians in the back...you have a responsibility to speak recklessly. Otherwise my kids may never know what reckless talk sounds like. The joys of being wrong." This controversial comedian, who had memorably retreated in 2006 from a reported 50 million dollar contract with Comedy Central and experienced for all of us to see, what sociologists of culture regularly publish on: 1) the reproductions, often more intensely and dramatically, of operating social structures and ideologies in any cultural or artistic expression and 2) the problems with counter-hegemonic messages and representations, or the relationship between structure and agency more generally.

\footnotetext{
${ }^{12}$ Chappelle released two comedy albums, The Age of Spin/Deep in the Heart of Texas and Equanimity/The Bird Revelation in 2017. Both albums were broadcast on Netflix's platform, reaching an estimated 300 million viewers (McAlone, 2017). Netflix also reported that The Age of Spin/Deep in the Heart of Texas was their most frequently viewed comedy special to date (Hibberd, 2017). It went on to win a Grammy in 2018, while Equanimity/The Bird Revelation secured an Emmy nomination.
} 
The limits of counter-hegemonic comedic criticisms of the status quo have been evidenced (Jacobs \& Wild, 2013). In their analysis of how the reigning "aesthetic public spheres" (The New York Times and The Washington Post) reacted to comedic challenges in the socio-political sphere (The Daily Show and The Colbert Report), Jacobs and Wild demonstrated the relative weakness in comedic challenges in the face of these collective meaning structures and cultural hierarchies. This is where the power of comedy of resides though. Subsuming comedy into the dominant, widely shared and accepted, cultural meaning structure would negate its very purpose. Along with Hegelian materialism of the spirit, and its associated negative power, "comic power" also possesses affirmative power that initiates, inspires, and empowers fresh, alternate conceptualizations and possibilities, previously deemed as authoritative, correct, or natural (Tonder, 2014). Nevertheless, sociological investigations into the relationships between societal responses, including "aesthetic public spheres", to these comedic challenges remain important. How do ruling cultural institutions and agents reply to mockery that is also socially mandated? Ultimately though, observing comedic challenges to hegemonic structures, in and of itself, equals expansion and disruption, whose mercurial ripple effects give vitality to the entirety of the societal spectrum, making "comic power", not an enemy of democratic continuity, but rather a cultural practice that possesses and distributes the qualities of democracy inherently (James, 2019; Tonder, 2014).

Cultural meanings are elemental to our social existence. Not submissive or accommodating to the material aspects of social life, cultural meanings pervade constitutive aspects, revealing the logic of a once confounding puzzle. The primacy, or at the very least, the urgency of the comprehension of cultural meanings encourages reflection and criticism, of the pertinence of the stories that dominate knowledge, and move toward the discernment between knowledge and power (Alexander, 2003; Robbins et al., 2019). The unfortunate split between the "serious" and the "comic" in our societal assessment of important cultural symbols and meanings betrays a more complete and nuanced viewpoint and comprehension. Advancing the particular contribution that humor offers social analysis, Davis (1993) noted how humor "may seem trivial, but it provides an inconspicuous back entrance to a person's, group's, or society's innermost chamber, which continually knocking on their front door may never disclose" (p. 2). The re-articulations of comedic interventions represent very serious planes of societal dimensions, in this particular analysis, a race ideology that consists of discrimination, dehumanization, and subordination. The language of comedy illuminates those dimensions of race ideology that are particularly constraining, particularly stubborn, and particularly inaccessible - a distinct contribution to the overarching and dominant cultural narratives and representations. The comic discursive and representational examples above demonstrate the processes of reclamation, and of the simultaneously occurring liminal moments of meaning-making and material expressions of collective cultural constructions.

\section{References}

Albanese, R., Bodow, S., Flanz, J., Greenberg, T., Javerbaum, D., Karlin, B., Katz, J., Lieb, J., Lowitt, A., Noah, T., Smithberg, M., \& Stewart, J. (Executive Producers). (1996-present). The daily show [TV series]. Ark Angel; Comedy Partners.

Alexander, J. C. (2003). The meanings of social life: A cultural sociology. Oxford University Press. Apatow, J. (Executive Producer). (1990-1991). The Ben Stiller show [TV series]. HBO Independent Productions.

Armour, M., Brennan, N., \& Chappelle, D. (Executive Producers). (2003-2006). Chappelle's show [TV series]. Pilot Boy Productions; Marobu Productions; Comedy Central Productions. 
Kim, J.

Bahr, F., Blasucci, D., Jones, Q., Salzman, D., \& Small, A. (Executive Producers). (1995-2009). Mad TV [TV series]. Bahr/Small Productions; Quincy Jones-David Salzman Entertainment.

Bahr, F., Campbell, G., Foxworthy, J., Hartt, B., \& Small, A. (Executive Producers). (2004-2006). Blue collar TV [TV series]. Bahr-Small Productions; Parallel Entertainment; Riverside Productions; Warner Bros. Productions.

Bakhtin, M. M., \& Holquist, M. (Eds.). (1981). The dialogic imagination: Four essays (C. Emerson \& M. Holquist, Trans.). University of Texas Press. (Original work published 1975).

Banner, B. \& Hamilton, J. (Executive Producers). (1967-1978). The Carol Burnett Show [TV series]. Burngood, Inc.; Punkin' Productions, Inc.; Whacko, Inc.

Berger, A. A. (1995). Blind men and elephants: Perspectives on humor. Transaction Publishers.

Biederman, J., Forristal, J., Michaels, L., \& Ross, J. (Executive Producers). (1984-present). The kids in the hall [TV series]. Broadway Video; Project 10.

Bowman, J., Kyles, C.A., \& Lathan, S. (Executive Producers). (2002-2003). Cedric the entertainer presents [TV series]. Regency Television; $20^{\text {th }}$ Century Fox Television.

Bryant, C. (2006). The language of resistance? Czech jokes and joke-telling under Nazi occupation, 1943-45. Journal of Contemporary History, 41(1), 133-151. http://dx.doi.org/10.1177/0022009406058687

Bryson, B. (1996). 'Anything but heavy metal': Symbolic exclusion and musical dislikes. American Sociological Review, 61(5), 884-899.

Burke, K. (1969). The grammar of motives. University of California Press.

Butler, J. (2008). Gender trouble: Feminism and the subversion of identity. Routledge Classics. (Original work published 1990).

Carsey, M., Kukoff, B., Leahy, J., \& Werner, T. (Executive Producers). (1984-1992). The Cosby show [TV series]. Carsey-Werner Productions; Bill Cosby Productions.

Chappelle, D. (Executive Producer). (2017). The bird revelation [TV special]. Pilot Boy Productions.

Chappelle, D., Lathan, S., Nishimura, L., \& Praw, R. (Executive Producers). (2017). The age of spin [TV special]. Lathan TV; Pilot Boy Productions.

Chappelle, D., Lathan, S., Nishimura, L., \& Praw, R. (Executive Producers). (2017). Deep in the heart of Texas [TV special]. Lathan TV; Pilot Boy Productions.

Chappelle, D., Lathan, S., Nishimura, L., \& Praw, R. (Executive Producers). (2017). Equanimity [TV special]. Lathan TV; Pilot Boy Productions.

Clawson, T. \& Loze, M. (Executive Producers). (1990-1991). The idiot box [TV series]. MTV.

Cohen, S.B., Fincham, P., \& Mazer, D. (Executive Producers). (2000-2004). Da Ali G show [TV series]. Talkback.

Colbert, S., Purcell, T., \& Stewart, J. (Executive Producers). (2005-2014). The Colbert report [TV series]. Busboy Productions; Comedy Partners; Spartina Productions.

Collins, P. H. (2000). Black feminist thought: Knowledge, consciousness, and the politics of empowerment (2nd ed.). Routledge.

Davis, C. (2020). Critical excess: Overreading in Derrida, Deleuze, Levinas, Zizek, and Cavell. Stanford University Press.

Davis, M. (1993). What's so funny?: The comic conception of culture and society. The University of Chicago Press.

Davola, J., Fields, G., Firestein, L., Veasey, P., \& Wayans, K.I. (Executive Producers). (19901994). In living color [TV series]. Ivory Way Productions. 
Diawara, M. (1988). Black spectatorship: Problems of identification and resistance. Screen: The Journal of the Society for Education in Film and Television, 29, 66-78. http://dx.doi.org/10.1093/screen/29.4.66

Emerson, R. (2005). 'Where my girls at?': Negotiating black womanhood in music videos. In D. M. Hunt (Ed.), Channeling Blackness: Studies on television and race in America. Oxford University Press.

Eyal, G., Szelenyi, I., \& Townsley, E. (2003). On irony: An invitation to neoclassical sociology. Thesis Eleven, 73, 5-41. http://dx.doi.org/10.1177/0725513603073001002

Friedman, S. \& Kuipers, G. (2013). The divisive power of humour: Comedy, taste, and symbolic

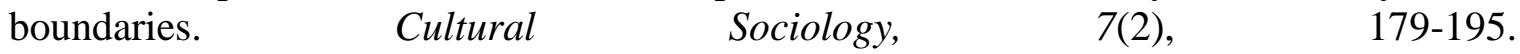
http://dx.doi.org/10.1177/1749975513477405

Fritz, K. (Executive Producer). (1967-1969). The Smothers brothers comedy hour [TV series]. Comedic Productions.

Gibbons, M., Hartt, B., McGuire, C., Mencia, C., \& Morton, R. (Executive Producers). (20052008). Mind of Mencia [TV series]. Comedy Central.

Gogan, B. (2009). Laughing whiteness: Pixies, parody, and perspectives. In K. A. Wisniewski (Ed.), The comedy of Dave Chappelle: Critical essays. McFarland \& Company.

Goldberg, A., Hannan, M. T., \& Kovacs, B. (2016). What does it mean to span cultural boundaries? Variety and atypicality in cultural consumption. American Sociological Review, 81(2), 215241. https://doi.org/10.1177/0003122416632787

Goldstein, D. M. (2003). Laughter out of place: Race, class, violence, and sexuality in a Rio shantytown. University of California Press.

Gray, H. (1995). Watching race: Television and the struggle for "Blackness." University of Minnesota Press.

Griffith, D.W. (Director). (1915). The birth of a nation [Film]. David W. Griffith Corp.

Guerrero, L. A. (2020). Crazy funny: Popular Black satire and the method of madness. Routledge.

Hall, S. (1989). Cultural identity and cinematic representation. Framework, 36, 68-82.

Harrison, K. (2017). Shakespeare, Bakhtin, and film: A dialogic lens. Springer International.

Hibberd, J. (2017, April 18). Netflix says Dave Chappelle specials are its most-watched ever. Entertainment Weekly. https://ew.com/tv/2017/04/18/netflix-dave-chappelle-specialsrecords/

Hill, W. (Director). (1982). 48 Hrs. [Film]. Lawrence Gordon Productions.

hooks, b. (1992). Black looks: Race and representation. South End Press.

hooks, b. (2003). Rock my soul: Black people and self-esteem. Atria Books.

Jacobs, R. N., \& Wild, N.M. (2013). A cultural sociology of 'The Daily Show and The Colbert Report.' American Journal of Cultural Sociology, l(1), 69-95. http://dx.doi.org/10.1057/ajcs.2012.7

James, W. Y. (2019). Imprint of Racism: White Adult Males' Transformational Experience from Racial Antipathy to Racial Reconciliation. American Journal of Qualitative Research, 3(1), 93-116. https://doi.org/10.29333/ajqr/5813

Jewison, N. (Director). (1984). A Soldier's Story [Film]. Columbia Pictures.

Jhally, S., \& Lewis, J. (1992). Enlightened racism: The Cosby show, audiences, and the myth of the American dream. Westview Press.

Kane, A. (1991). Cultural analysis in historical sociology: The analytic and concrete forms of the autonomy of culture. Sociological Theory, 9(1), 53-69. http://dx.doi.org/10.2307/201873 
Kim, J.

Kataria, S. (2020). Identifying The Key Contributory Factors Behind Ethno-national Conflict. Journal of Ethnic and Cultural Studies, 7(2), 110-126. http://dx.doi.org/10.29333/ejecs/366

Kay, M. (Executive Producer). (1970-1974). The Flip Wilson show [TV series]. Rhino Entertainment.

Kellner, D. (2020). Media culture: Cultural studies, identity, and politics in the contemporary moment. Routledge.

Krefting, R. (2014). All joking aside: American humor and its discontents. Johns Hopkins University Press.

LaPaglia, K. (2018). Book Review: Critical pedagogy: Notes from the real world. American Journal of Qualitative Research, 2(2), 150-153.

McAlone, N. (2017, October 26). Netflix says it now has over 300 million 'viewers'. Business Insider. https://www.businessinsider.com/netflix-has-300-million-viewers-2017-10

Michaels, L. (Executive Producer). (1975-present). Saturday night live [TV series]. Broadway Video.

Mukherjee, R., Banet-Weiser, S., \& Gray, H. (Eds.). (2019). Racism post-race. Duke University Press.

Nagel, J. (2003). Race, ethnicity, and sexuality: Intimate intersections, forbidden frontiers. Oxford University Press.

Omi, M. \& Winant, H. (2015). Racial formation in the United States (3rd ed.). Routledge.

Perez, R. (2013). Learning to make racism funny in the 'color-blind' era: Stand-up comedy students, performance strategies, and the (re)production of racist jokes in public. Discourse \& Society, 24(4), 478-503.

Perinbanayagam, R. S. (2000). The presence of self. Roman \& Littlefield.

Pescosolido, B. A., Grauerholz, E., \& Milkie, M. A. (1997). Culture and conflict: The portrayal of blacks in U.S. children's picture books through the mid- and late-twentieth century. American Sociological Review, 62(3), 443-464. http://dx.doi.org/10.2307/2657315

Quirk, S. (2015). Why stand-up matters: How comedians manipulate and influence. Methuen Drama.

Rehak, J. K., \& Trnka, S. (Eds.). (2019). Politics of joking: Anthropological engagements. Routledge.

Robbins, C., Bishop, J., \& Tarman, B. (2019). Against Reactionary Populism: Opening a Needed Conversation in Education. Journal of Culture and Values in Education, 2(3), i-vi. https://doi.org/10.46303/jcve.03.02.ed

Smith, A. (2020). Critical Race Theory: Disruption in Teacher Education Pedagogy. Journal of Culture and Values in Education, 3(1), 52-71. https://doi.org/10.46303/jcve.03.01.4

Smith, D. R. (2018). Comedy and critique: Stand-up comedy and the professional ethos of laughter. Bristol University Press.

Smith, D. R. (2019). Stand-up comedy and the comedic cult of the individual: or, the humor of James Acaster. American Journal of Cultural Sociology. https://doi.org/10.1057/s41290019-00082-x

Spielberg, S. (Director). (1985). The color purple [Film]. Amblin Entertainment.

Stallone, S. (Director). (1979). Rocky II [Film]. Chartoff-Winkler Productions.

Takaki, R. (2000). Iron cages: Race and culture in 19th-century America. Oxford University Press.

Tonder, L. (2014). Comic power: Another road not taken? Theory \& Event, 17(4). http://libproxy.temple.edu/login?url=https://www-

proquest.com.libproxy.temple.edu/docview/1637636142?accountid=14270 
Urbisci, R. (Producer). (1977). The Richard Pryor show [TV series]. Burt Sugarman Productions. Weaver, S. (2010). Developing a rhetorical analysis of racist humour: Examining anti-black jokes on the internet. Social Semiotics, 20(5), 537-555. http://dx.doi.org/10.1080/10350330.2010.513188

Weaver, S. (2011). The rhetoric of racist humour: US, UK, and global race joking. Ashgate Publishing Limited.

Welcome, A. H. (2010). Our bodies for ourselves: Lithe phenomenal bodies in the stand-up of Jackie 'Moms' Mabley. Black Women, Gender \& Families, 4(1), 87-101.

Wildes, A. (2020). The Unethical Practice of Omitting Language in State Science Standards: Denying Students True Democratic Freedom. Journal of Curriculum Studies Research, 2(1), 112-128. https://doi.org/10.46303/jcsr.02.01.7

Yi, S., \& Hoston, W. T. (2020). Demystifying Americanness: The model minority myth and the black-Korean relationship. Journal of Ethnic and Cultural Studies, 7(2), 68-89. http://dx.doi.org/10.29333/ejecs/350

Zupancic, A. (2008). The odd one in: On comedy. The MIT Press.

\section{Notes on Contributors}

Jennifer Kim has a $\mathrm{PhD}$ in Sociology from Temple University and a BA in Sociology \& Anthropology with a minor in Black Studies from Swarthmore College. She is currently preoccupied with research on comedy. Her dissertation research examined five decades of transformative sketch comedy in the US from 1960-2000, with an intersectional focus on race and racism. She is working on her first book on the inner-lives of comedians based on an ethnographic study at The Comedy Store in La Jolla, CA and life story interviews. 